\title{
Early detection of leprosy by examination of household contacts, determination of serum anti-PGL-1 antibodies and consanguinity
}

\author{
Renata Bazan-Furini', Ana Carolina F Motta' ${ }^{1}{ }^{+}$, João Carlos L Simão', Daniela Chaves Tarquínio', \\ Wilson Marques Jr², Marcello Henrique N Barbosa ${ }^{3}$, Norma Tiraboschi Foss ${ }^{1}$ \\ 'Divisão de Dermatologia ${ }^{2}$ Divisão de Neurologia ${ }^{3}$ Divisão de Radiologia, \\ Faculdade de Medicina de Ribeirão Preto, Universidade de São Paulo, Av. Bandeirantes 3900, 14049-900 Ribeirão Preto, SP, Brasil
}

\begin{abstract}
A cross-sectional clinical trial in which the serum anti-phenolic glycolipid (anti-PGL-1) antibodies were analysed in household contacts (HHC) of patients with leprosy as an adjunct early leprosy diagnostic marker was conducted. The families of 83 patients underwent clinical examination and serum anti-PGL1 measurement using enzyme-linked immunosorbent assay. Of 320 HHC, 98 were contacts of lepromatous leprosy (LL), 80 were contacts of borderline lepromatous (BL), 28 were contacts of borderline (BB) leprosy, 54 were contacts of borderline tuberculoid (BT), 40 were contacts of tuberculoid (TT) and 20 were contacts of indeterminate (I) leprosy. Consanguinity with the patients was determined for 232 (72.5\%) HHC. Of those 232 contacts, 183 had linear consanguinity. Forty-nine HHC had collateral consanguinity. Fifty-eight contacts (18.1\%) tested positive for anti-PGL1 antibodies. The number of seropositive contacts based on the clinical forms of the index case was 17 (29.3\%) for $L L, 15$ (25.9\%) for BL, one (1.7\%) for BB, 14 (24.1\%) for BT, three (5.2\%) for TT and eight (13.7\%) for I. At the one year follow-up, two (3.4\%) of these seropositive contacts had developed BT leprosy. The results of the present study indicate that the serum anti-PGL-1 IgM antibody may be useful for evaluating antigen exposure and as a tool for an early leprosy diagnosis in HHC.
\end{abstract}

Key words: leprosy - household contacts - early detection - anti-PGL-1 - consanguinity

Leprosy is a chronic infectious disease caused by Mycobacterium leprae, an acid-fast bacillus that presents a peculiar tropism for peripheral nerves and the skin. The prevalence of leprosy in the world has declined since the introduction of the multidrug therapy recommended by the World Health Organization (WHO 1982). However, leprosy is still a public health problem, especially in Brazil, where the number of new cases is high (37,610 cases in 2009) (WHO 2010).

Significant progress has been made in controlling leprosy and reducing the burden of the disease; however, there is much that is still required to reduce the disease burden. Early case identification is one of the aims of leprosy control programs (Oskam et al. 2003, WHO 2009). Thus, controlled clinical trials conducted on household contacts (HHC) are of great importance for the detection of new disease cases (Foss et al. 1993, Goulart et al. 2008). With this idea in mind, we undertook the study of examining the anti-PGL-1 antibody levels in HHC of leprosy patients.

Leprosy diagnosis is based on clinical examination, bacterial index, histopathological findings (Ridley \& Jopling 1966) and the serologic determination of anti-

Financial support: The Foundation for the Support of Teaching, Research and Assistance of HCFMRP-USP (FAEPA), CNPq (401001/2005-9), The São Paulo State Foundation against Leprosy (0102)

+ Corresponding author: anacfm@usp.br

Received 11 September 2010

Accepted 1 July 2011 bodies. The phenolic glycolipid antibody (PGL-1), as measured using an enzyme-linked immunosorbent assay (ELISA), is considered to be a relevant marker of leprosy activity (Burgess et al. 1988, Zenha et al. 2009, Frota et al. 2010). The PGL-1 fraction is part of the cell envelope of $M$. leprae and induces the production of the specific humoral response against PGL-1 detected in patient serum (Hunter et al. 1982, Cho et al. 1983, Foss et al. 1993). When the antibody is present at high levels, it can be inferred that the infection is active, especially during the reactional episodes that constitute a very common complication in the evolution of leprosy (Chin-A-Lein et al. 1992, Goulart et al. 2002).

With the current emphasis on strategies leading to an early diagnosis of leprosy in the world (WHO 2009), we need laboratory markers to detect leprosy in patients during the early stages of the disease and to help reduce the disability and deformities caused by permanent nerve damage. Thus, the present cross-sectional clinical trial was conducted to analyse the serum titres of anti-PGL-1 antibodies as an adjunct tool for early leprosy diagnosis among leprosy HHC.

\section{PATIENTS, MATERIALS AND METHODS}

Patients - The families of leprosy patients being treated at the Leprosy Clinics of the School of Medicine of Ribeirão Preto (HCRP), University of São Paulo, were recruited. Those who agreed to participate in the study were rescheduled for a clinical examination (nerve thickness, cutaneous lesions and sensitivity) by an experienced examiner and for serum anti-PGL-1 measurement. Subjects were excluded if they presented with co-existing local or 
systemic infection and/or any disease that could affect the peripheral nervous system such as diabetes mellitus and alcoholism. The trial was approved by the local Ethical Committee (HCRP 13.549/2005) and all subjects provided written informed consent to participate.

Serum antibody titres - Ninety-six-well polystyrene plates (Costar, Cambridge, USA) were coated with antigen (PGL-1, kindly provided by Dr JS Spencer, Colorado University, USA) in sodium carbonate buffer $(2 \mu \mathrm{g} / \mathrm{mL})$, $\mathrm{pH} 9.6$ and stored at $4^{\circ} \mathrm{C}$ until used. The serum from each patient was diluted 1:100 in $15 \mathrm{mM}$ Tris-Tween buffer containing $5 \%$ sheep serum, $10 \mu \mathrm{L}$ were added to each well and the plate was incubated for $1 \mathrm{~h}$ at $37^{\circ} \mathrm{C}$ in a humidified chamber. At the end of the hour, the samples were washed with $15 \mathrm{mM}$ Tris-Tween buffer and antihuman IgM beta-galactosidase conjugate (Sigma, USA) diluted 1:600 in $15 \mathrm{mM}$ Tris-Tween buffer containing $5 \%$ sheep serum. The plates were incubated at $37^{\circ} \mathrm{C}$ for $1 \mathrm{~h}$. A fluorogenic substrate ( $10 \mu \mathrm{L} 4$-methylumbelliferyl beta- $\mathrm{D}$-galactopyranoside) was then added to the samples and the material was incubated at $37^{\circ} \mathrm{C}$ for $30 \mathrm{~min}$. The plate was read with a multiscan ELISA reader. Sera samples with an absorbance at $450 \mathrm{~nm}$ greater than 0.028 [the mean absorbance plus 3 standard deviations (SD) of 40 healthy Brazilian control subjects] were considered positive. Each serum sample was tested in duplicate.

Follow-up - All HHC have received follow-up examinations at the Leprosy Clinics at six-month intervals since 2005 .

Statistical analysis - Odds ratios and a Fisher's exact test were used to test for differences between the groups that presented anti-PGL-1 levels $\geq$ or $<$ cut-off (positive and negative levels, respectively) with the aid of the Statistical Analysis System - SAS ${ }^{\circledR} 9.0$ software (San Diego, Cary, NC, USA). Significance was set at $\mathrm{p}<0.05$.

\section{RESULTS}

Characteristics of the study population - Eighty-three families agreed to participate in the study. Of these families, $331 \mathrm{HHC}$ were examined and 11 were diagnosed as leprosy patients: two patients presented lepromatous leprosy (LL), four presented the tuberculoid form (TT) and five presented the indeterminate form (I). The final study population sample enrolled consisted of $320 \mathrm{HHC}$ of leprosy patients (130 men and 190 women, mean \pm SD age $27.01 \pm 19.57$ years, range 1-81 years). HHC were grouped according to anti-PGL-1 levels. The characteristics of the patients are listed in Table I. Among the 83 leprosy patients, 25 presented LL, 20 presented borderline lepromatous (BL), seven were borderline (BB), 16 were borderline tuberculoid (BT), nine were TT and six were I.

Profile of HHC - Ninety-eight HHC were contacts of LL patients, 80 of BL patients, 28 of BB patients, 54 of BT patients, 40 of TT patients and 20 of I leprosy patients. Two-hundred-and-thirty-two HHC had some level of relationship, i.e., linear consanguinity with the index case in 183 contacts and collateral consanguinity in 49 contacts. The other $88 \mathrm{HHC}$ had an affinity relationship.
Serum antibody titres - Of the 320 contacts, 58 (18.1\%) had positive anti-PGL-1 levels. The anti-PGL-1 seropositivity levels among the contacts based on the clinical forms of the index case inside the household were 17 (29.3\%) for LL, 15 (25.9\%) for BL, one (1.7\%) for BB, 14 (24.1\%) for BT, three (5.2\%) for TT and eight (13.7\%) for I. Serum anti-PGL-1 IgM antibodies were higher among female HHC (35) than among male HHC (23) (Table II).

Follow-up - All of the HHC are being followed at six-month intervals at the Leprosy Clinics, especially the seropositive contacts. After one year of follow-up, two seropositive contacts with confirmed linear consanguinity developed BT leprosy.

\section{DISCUSSION}

In the present study, we first evaluated HHC of leprosy patients and detected 11 new leprosy cases $(3.3 \%$ of the contacts) based on the clinical examination. The cases were later confirmed with histopathological examination and bacilloscopic index, emphasising the importance of examining $\mathrm{HHC}$ for an early diagnosis (5 cases of I) and for the detection of occult prevalence (2 cases of LL) in a non-endemic region, as the leprosy prevalence in Ribeirão Preto is $0.89 / 10,000$ habitants in 2009 (SINAN 2010). Similar results were reported by CardonaCastro et al. (2005), who detected two multibacillary (MB) leprosy cases among the HHC from a Colombian region considered to be in the post-elimination phase. Therefore, we emphasise that the evaluation of $\mathrm{HHC}$ is a useful tool for leprosy control not only in endemic areas, but also in non-endemic areas.

In the present study, in an attempt to improve early detection, the levels of anti-PGL-1 antibodies were assessed in serum samples from HHC of leprosy patients, as an adjunct to the determination of antigen exposure. The median age was similar for both seropositive and seronegative cases. The proportion of anti-PGL-1-seropositive HHC among the different clinical forms was different from the proportion previously reported in some studies conducted in endemic areas (Gonzalez-Abreu et al. 1990, Ulrich et al. 1991, Cellona et al. 1993). Although these studies found no differences in seropositivity rates among HHC of MB and paucibacillary leprosy (PB) leprosy patients, our results indicated a slight difference in serum anti-PGL-1 IgM seropositivity rates between HHC of MB leprosy patients (56.8\%) and of PB leprosy patients $(43.1 \%)$, especially when comparing I leprosy patients $(14 \%)$ x LL leprosy patients $(29 \%)(\mathrm{p}=0.03)$. Similar results were reported by Calado et al. (2005), Carbona-Castro et al. (2008) and Frota et al. (2010). The presence of serum antibodies suggests that the PGL-1 antigen induced a humoral immune response, but these increased antibody concentrations apparently could not block M. leprae multiplication in the host (Kaplan \& Chase 1980, Touw et al. 1982), as we found that two cases progressed to BT leprosy after one year of followup of these seropositive contacts.

The results suggest a useful role for the measurement of serum M. leprae-specific anti-PGL-1 IgM antibodies. The measurement can be used as an easy, 
TABLE I

Clinical data of the leprosy patients and their household contacts (HHC)

\begin{tabular}{|c|c|c|}
\hline Variables & $\begin{array}{l}\text { Index case } \\
\mathrm{n}=83(\%)\end{array}$ & $\begin{array}{c}\text { HHC } \\
n=320(\%)\end{array}$ \\
\hline \multicolumn{3}{|l|}{ Gender } \\
\hline Male & $58(69.8)$ & $130(40.6)$ \\
\hline Female & $25(30.1)$ & $190(59.4)$ \\
\hline \multicolumn{3}{|l|}{ Age } \\
\hline Mean (range) & $51.46 \pm 14.60(9-75)$ & $27.01 \pm 19.57(1-81)$ \\
\hline Clinical classification & & HHC based on index case \\
\hline Indeterminate leprosy & $6(7.2)$ & $20(6.2)$ \\
\hline Tuberculoid leprosy & $9(10.8)$ & $40(12.5)$ \\
\hline Borderline tuberculoid & $16(19.2)$ & $54(16.8)$ \\
\hline Borderline leprosy & $7(8.4)$ & $28(8.7)$ \\
\hline Borderline lepromatous & $20(24)$ & $80(25)$ \\
\hline Lepromatous leprosy & $25(30.1)$ & $98(30.6)$ \\
\hline \multicolumn{3}{|l|}{ Operational classification } \\
\hline Paucibacillary leprosy & $31(37.3)$ & $114(35.6)$ \\
\hline Multibacillary leprosy & $52(62.6)$ & $206(64.4)$ \\
\hline
\end{tabular}

\section{TABLE II}

Clinical data and anti-glycolipid antibody (PGL-1) titres of the household contacts (HHC) of leprosy patients

\begin{tabular}{|c|c|c|c|c|c|}
\hline \multirow[t]{2}{*}{ Variables } & \multicolumn{2}{|c|}{$\begin{array}{l}\mathrm{HHC} \\
\mathrm{n}(\%)\end{array}$} & \multirow[t]{2}{*}{ Total } & \multirow[t]{2}{*}{$\begin{array}{c}\text { Odds-ratio } \\
(95 \% \mathrm{CI})\end{array}$} & \multirow[t]{2}{*}{$\mathrm{p}$ value } \\
\hline & Anti-PGL-1 $<0.03^{a}$ & Anti-PGL-1 $\geq 0.03^{a}$ & & & \\
\hline \multicolumn{6}{|l|}{ Gender } \\
\hline Male & $107(40.8)$ & $23(39.7)$ & 130 & $1.155(0.644-2.073)$ & 0.72 \\
\hline Female & $155(57.2)$ & $35(60.3)$ & 190 & & \\
\hline \multicolumn{6}{|l|}{ Age } \\
\hline Mean (range) & $26.64 \pm 19.23(1-81)$ & $28.06 \pm 19.72(1-81)$ & - & - & - \\
\hline \multicolumn{6}{|c|}{ Clinical classification of the index case } \\
\hline Indeterminate leprosy & $12(4.5)$ & $08(13.7)$ & 20 & $3.176(1.127-8.953)$ & 0.03 \\
\hline Tuberculoid leprosy & $37(14.1)$ & $03(5.2)$ & 40 & $0.386(0.107-1.400)$ & \\
\hline Borderline tuberculoid & $40(15.2)$ & $14(24.1)$ & 54 & $1.549(0.685-3.500)$ & \\
\hline Borderline leprosy & $27(10.3)$ & $01(1.7)$ & 28 & $0.367(0.079-1.694)$ & \\
\hline Borderline lepromatous & $65(24.8)$ & $15(25.9)$ & 80 & $1.083(0.503-2.331)$ & \\
\hline Lepromatous leprosy ${ }^{b}$ & $81(30.9)$ & $17(29.3)$ & 98 & - & \\
\hline \multicolumn{6}{|l|}{ Operational classification } \\
\hline Paucibacillary leprosy & $89(34)$ & $25(43.1)$ & 114 & $0.733(0.410-1.312)$ & 0.29 \\
\hline Multibacillary leprosy & $173(66)$ & $33(56.9)$ & 206 & & \\
\hline \multicolumn{6}{|c|}{ Relationship with the index case } \\
\hline Consanguinity $^{c}$ & $187(70.6)$ & $45(81.8)$ & 232 & - & 0.06 \\
\hline Linear $^{d}$ & 153 & 30 & 183 & - & \\
\hline Collateral & 34 & 15 & 49 & $2.129(1.039-4.363)$ & \\
\hline Affinity $^{e}$ & $78(29.4)$ & $10(18.2)$ & 88 & $0.817(0.397-1.681)$ & \\
\hline
\end{tabular}

$a$ : cut-off; $b$ : clinical form; $c$ : relationship by blood; $d$ :relationship used as reference for comparison between the others; $e$ : relationship by marriage; CI: confidence interval. 
non-invasive and inexpensive adjunct method for the detection of leprosy in the population, as reported previously (Foss et al. 1993, Frota et al. 2010). In addition, the results suggest an important role for the measurement of serum anti-PGL-1 antibodies as a method for detecting subclinical infection, especially in leprosy contacts with low or no resistance to M. leprae (Foss et al. 1993). As seropositivity for IgM anti-PGL-1 might be a risk factor for developing leprosy, the seropositive individuals should be monitored via clinical examination, determination of the immune response and bacteriologic state for leprosy detection (Douglas et al. 2004, Cardona-Castro et al. 2009), as was done with the HHC selected in the present study.

There are some risk factors for the development of leprosy, in addition to being a contact, such as clinical form of leprosy of the index case, the physical distance and the consanguinity (Richardus et al. 2005, Moet et al. 2006). Consanguinity is the relationship between members from the same family and it can be classified as linear and collateral. Linear consanguinity is the blood relationship that exists among persons, where one person is descended from the other and proceeds upwards in a direct ascending line, whereas collateral consanguinity is the relation subsisting among persons who are descended from the same common ancestor, but not from each other. Affinity was considered to be a relationship by marriage. The importance of consanguinity for the development of anti-PGL-1 IgM antibodies should be emphasised as most of the contacts with positive antiPGL-1 titres (45/58) had a family history of leprosy. In addition, the two cases that developed BT leprosy had a confirmed linear consanguinity with the index case.

The results of this study indicate that in a low-prevalence area a high proportion of HHC of leprosy patients are at an increased risk of developing leprosy (CardonaCastro et al. 2005, 2008, Dessunti et al. 2008). In conclusion, the clinical evaluation and serum measurements of anti-PGL-1 IgM are useful for the evaluation of antigen exposure. The follow-up of HHC with high levels of anti-PGL-1 IgM could facilitate the characterisation of those contacts who are at risk of developing leprosy, particularly in cases of linear consanguinity.

\section{ACKNOWLEDGEMENTS}

To the authors, for the participation of the patients and communities, and to Mr Mario Ignácio Neto, for assistance with sample analysis.

\section{REFERENCES}

Burgess PJ, Fine PE, Ponnighaus JM, Draper C 1988. Serological tests in leprosy. The sensitivity, specificity and predictive value of ELISA tests based on phenolic glycolipid antigens and the implications for their use in epidemiological studies. Epidemiol Infect 101: 159-171.

Calado KLS, Vieira AG, Durães S, Sékula SB, Oliveira MLW 2005. Seropositivity with anti-PGL-1 of household and neighbours contacts of leprosy patients in an urban area. An Bras Dermatol 80 (Suppl. 3): S301-306.

Cardona-Castro N, Beltrán-Alzate JC, Manrique-Hernández R 2008. Survey to identify Mycobacterium leprae-infected household contacts of patients from prevalent regions of leprosy in Colombia. Mem Inst Oswaldo Cruz 103: 332-336.

Cardona-Castro N, Beltrán-Alzate JC, Romero-Montoya M 2009. Clinical, bacteriological and immunological follow-up of household contacts of leprosy patients from a post-elimination area Antioquia, Colombia. Mem Inst Oswaldo Cruz 104: 935-936.

Cardona-Castro NM, Restrepo-Jaramillo S, Gil de la OM, Brennan PJ 2005. Infection by Mycobacterium leprae of household contacts of lepromatous leprosy patients from a post-elimination leprosy region of Colombia. Mem Inst Oswaldo Cruz 100: 703-707.

Cellona RV, Walsh GP, Fajardo TT Jr, Abalos RM, la Cruz EC, GuidoVillahermosa L, Felicio-Balagon MV, Steenbergen GJ, Douglas JT 1993. Cross-sectional assessment of ELISA reactivity in leprosy patients, contacts and normal population using the semisynthetic antigen natural disaccharide octyl bovine serum albumin (ND-O-BSA) in Cebu, the Philippines. Int J Lepr Other Mycobact Dis 61: 192-198.

Chin-A-Lein RA, Faber WR, van Rens MM, Leiker DL, Naafs B, Klatser PR 1992. Follow-up of multibacillary leprosy patients using phenolic glycolipid-I based ELISA. Do increasing ELISAvalues after discontinuation of treatment indicate relapse? Lepr Rev 63: 21-27.

Cho SN, Yanagihara DL, Hunter SW, Gelber RH, Brennan PJ 1983. Serological specificity of phenolic glycolipid-I from Mycobacterium leprae and use in serodiagnosis of leprosy. Infect Immun 41: $1077-1083$.

Dessunti EM, Soubhia Z, Alves E, Aranda CM, Barro MPAA 2008. Leprosy: control of household contacts in the municipality of Londrina-PR for a ten-year period. Rev Bras Enferm 61: 689-693.

Douglas JT, Cellona RV, Fajardo Jr TT, Abalos RM, Balagon MV, Klatser PR 2004. Prospective study of serological conversion as a risk factor for development of leprosy among household contacts. Clin Diagn Lab Immunol 11: 897-900.

Foss NT, Callera F, Alberto FL 1993. Anti-PGL-1 levels in leprosy patients and their contacts. Braz J Med Biol Res 26: 43-51.

Frota CC, Freitas MVC, Foss NT, Lima LNC, Rodrigues LC, Barreto ML, Ligia RS, Kerr 2010. Seropositivity to anti-phenolic glycolipid-I in leprosy cases, contacts and no known contacts of leprosy in an endemic and a non-endemic area in Northeast Brazil. Trans $R$ Soc Trop Med Hyg 104: 490-495.

Gonzalez-Abreu E, Mora N, Perez M, Pereira M, Perez J, Gonzalez AB 1990. Serodiagnosis of leprosy in patients' contacts by enzyme-linked immunosorbent assay. Lepr Rev 61: 145-150.

Goulart IMB, Penna GO, Cunha G 2002. Imunopatologia da hanseníase: a complexidade dos mecanismos da resposta imune do hospedeiro ao Mycobacterium leprae. Rev Soc Bras Med Trop 35: 365-375.

Goulart IMB, Souza DOB, Marques CR, Pimenta VL, Gonçalves MA, Goulart LR 2008. Risk and protective factors for leprosy development determined by epidemiological surveillance of household contacts. Clin Vaccine Immunol 15: 101-305.

Hunter SW, Fujiwara T, Brennan PJ 1982. Structure and antigenicity of the major specific glycolipid antigen of Mycobacterium leprae. J Biol Chem 257: 15072-15078.

Kaplan MH, Chase MW 1980. Antibodies to Mycobacterium in human tuberculosis. II. Response to nine defined mycobacterial antigen with evidence for an antibody common to tuberculosis and lepromatous leprosy. J Infec Dis 142: 835-843.

Moet FJ, Pahan D, Schuring RP, Oskam L, Richardus JH 2006. Physical distance, genetic relationship, age and leprosy classification 
are independent risk factors for leprosy in contacts of patients with leprosy. J Infect Dis 193: 346-353.

Oskam L, Slim E, Buhrer-Sekula S 2003. Serology: recent developments, strengths, limitations and prospects: a state of the art overview. Lepr Rev 74: 196-205.

Richardus JH, Meima A, van Marrewijk CJ, Croft RP, Smith TC 2005. Close contacts with leprosy in newly diagnosed leprosy patients in a high and low endemic area: comparison between Bangladesh and Thailand. Int J Lepr Other Mycobact Dis 73: 249-257.

Ridley DS, Jopling WH 1966. Classification of leprosy according to immunity: a five group system. Int J Lepr 34: 255-273.

SINAN - Sistema Nacional de Agravos de Notificação 2010. [accessed 17 January 2011]. Available from: dtr2004.saude.gov.br/ sinanweb/index.php.

Touw J, Langendiyk EJM, Stoner GL, Belehu A 1982. Humoral immunity in leprosy: immunoglobulin $\mathrm{G}$ and $\mathrm{M}$ antibody responses to Mycobacterium leprae in relation to various disease patterns. Infect Immun 36: 885-892.

Ulrich M, Smith PG, Sampson C, Zuniga M, Centeno M, Garcia V, Manrique X, Salgado A, Convit J 1991. IgM antibodies to native phenolic glycolipid-1 in contacts of leprosy patients in Venezuela: epidemiological observations and a prospective study of the risk of leprosy. Int J Lepr Other Mycobact Dis 59: 405-415.

WHO - World Health Organization 1982. Chemotherapy of leprosy for control programmes. Tech Rep Ser 675: 1-33.

WHO - World Health Organization 2009. Global leprosy situation 2009. Wkly Epidemiol Rec 84: 333-340.

WHO - World Health Organization 2010. Global leprosy situation 2010. Wkly Epidemiol Rec 85: 337-348.

Zenha EM, Ferreira MA, Foss NT 2009. Use of anti-PGL-1 antibodies to monitor therapy regimes in leprosy patients. Braz J Med Biol Res 42: 968-972. 